\title{
Titanium Sponge Production Method by Kroll Process at OTC
}

\author{
Kotaro Nakamura ${ }^{*}$, Takahiro Iida, Nobuo Nakamura and Tadao Araike \\ Osaka Titanium Technologies Co., Ltd., Amagasaki 660-8533, Japan
}

\begin{abstract}
Titanium sponge is industrially produced by the Kroll process. OTC has been manufacturing titanium sponge using the Kroll process since 1952 and now has the capacity to produce 40,000 ton of titanium sponge a year. Titanium sponge made by the Kroll process is widely used, but that used for aircraft parts is ranked Premium Quality (PQ) grade and only a few producers, including OTC, can make it because of the high reliability required. Demand for PQ grade titanium sponge is increasing, so cost reductions within the Kroll process are needed. OTC has reduced costs by using middle-to-low-grade raw materials, producing the world's largest sponge cake, and improving productivity. [doi:10.2320/matertrans.MK201634]
\end{abstract}

(Received November 1, 2016; Accepted December 27, 2016; Published February 25, 2017)

Keywords: titanium sponge, Kroll process

\section{Introduction}

It has been almost 70 years since the first industrial production of titanium began in 1947 in the USA. OSAKA Titanium technologies Co., Ltd. (OTC) began manufacturing titanium sponge by the Kroll process in 1952.

Table 1 shows the history of OTC. OTC has the capacity to produce 40,000 ton of titanium sponge annually and achieved a cumulative total output of 600,000 ton in 2016.

Titanium sponge made by the Kroll process is widely used in applications such as aircraft (engines and fuselages), plants (electric power plants, desalination plants, and heat exchangers), consumer products (eye-glass frames and golf clubs),

Table 1 Chronological table of OTC milestones in titanium sponge production.

\begin{tabular}{cl}
\hline Year & \multicolumn{1}{c}{ Key events } \\
\hline 1952 & Built the first titanium pilot plant in Japan. \\
\hline 1977 & Completed reduction/separation furnaces (2-ton batch). \\
\hline 1978 & $\begin{array}{l}\text { Commenced operation of integrated titanium U-furnace } \\
\text { (5-ton batch). }\end{array}$ \\
\hline 2006 & $\begin{array}{l}\text { Increased annual production capacity of titanium sponge } \\
\text { to 24,000 ton. }\end{array}$ \\
\hline 2011 & $\begin{array}{l}\text { Increased annual production capacity of titanium sponge } \\
\text { to 40,000 ton. }\end{array}$ \\
\hline 2016 & Achieved cumulative total output of 600,000 ton. \\
\hline
\end{tabular}

electronic components and so on.

On a special note, both the number of commercial airplanes to be delivered and the ratio of titanium content per aircraft are increasing. Figure 1 shows the changes in delivery volumes of commercial aircraft and the demand for titanium used in aircraft over the years. There is increasing demand for titanium. Taking this demand into account, OTC is improving its sponge titanium productivity and cost efficiency. Many technological improvements are introduced in this paper.

\section{Kroll Process}

Figure 2 shows the Kroll process flow. The Kroll process consists of four processes. ${ }^{1-6)}$

i. Chlorination and purification of titanium ore

The raw materials are chlorinated and distillated to produce pure titanium tetrachloride $\left(\mathrm{TiCl}_{4}\right)$.

ii. Reduction and vacuum separation

Pure titanium tetrachloride is reduced using molten magnesium to produce titanium sponge and fed to vacuum distillation to remove residual magnesium and magnesium chloride $\left(\mathrm{MgCl}_{2}\right)$ in the titanium cake.

iii. Electrolysis of magnesium chloride

The magnesium chloride, which is a by-product of the reduction reaction, is decomposed into magnesium and chlorine gas. This magnesium and chlorine gas are reused in the reduction and chlorination processes.

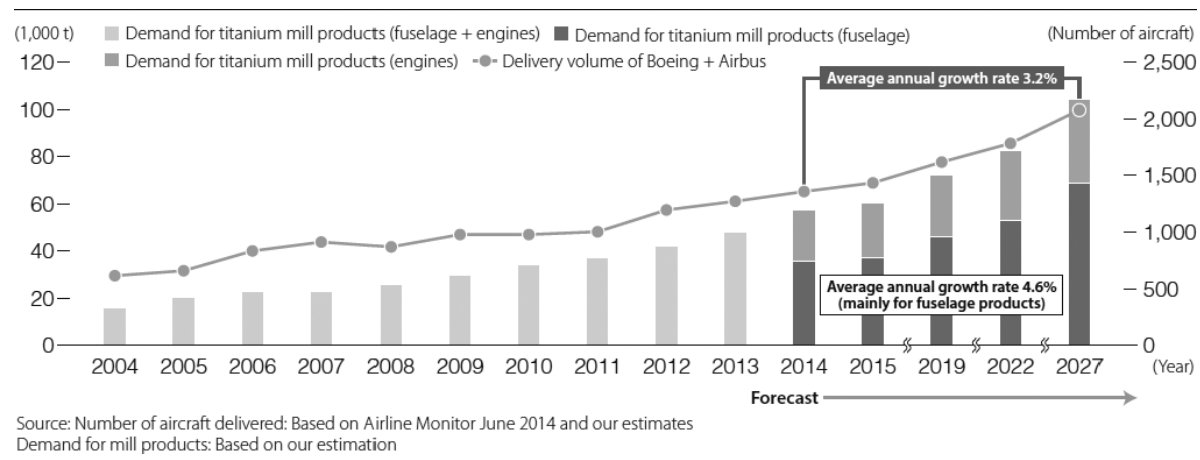

Fig. 1 Results and forecast of delivery volumes of commercial aircraft and demand for titanium mill products. 




Fig. 2 Kroll process flow.

iv. Crushing and sizing the titanium sponge cake

The sponge cake is crushed by a guillotine press machine, shearing machine, and jaw crusher. Then, the crushed titanium is blended and packaged into a drum.

\subsection{Chlorination and purification of titanium ore}

Figure 3 shows the $\mathrm{TiCl}_{4}$ process flow. Titanium ore and coke are fed into the chlorinator. Chlorine gas is blown into the chlorinator. The chlorination reaction is caused according to eq. (1).

$$
\mathrm{TiO}_{2}+\mathrm{C}+2 \mathrm{Cl}_{2} \rightarrow \mathrm{TiCl}_{4}+\mathrm{CO} / \mathrm{CO}_{2}
$$

Titanium ore is stripped of its oxygen and binds with the chlorine, forming crude titanium tetrachloride.

Next, the crude $\mathrm{TiCl}_{4}$ is distilled to remove impurities. In this process, highly purified $\mathrm{TiCl}_{4}$ is produced from ore that contained impurities. The purity standard of pure $\mathrm{TiCl}_{4}$ is $5 \mathrm{~N}$ $\mathbf{( 9 9 . 9 9 9 \% )}$ grade, therefore a large amount of impurities are removed in this process.

The raw materials account for a large portion of the titanium sponge production costs.

Therefore, we radically advanced our technologies to utilize relatively low cost, middle-to-low-grade raw materials.

Establishing technologies for sorting and mixing raw materials, and stabilizing chlorinator operation enabled OTC to blend about $70 \%$ middle-to-low-grade raw materials in the process. OTC successfully developed technologies that enabled the use of middle-to-low-grade materials without sacrificing quality.

\subsection{Reduction and vacuum separation}

Figure 4 shows the process flow of reduction and vacuum separation.

After molten magnesium is fed into the vessel, liquid titanium tetrachloride is fed into the vessel and a reduction reaction is caused to obtain titanium sponge. The reaction formula is shown in eq. (2).

$$
\mathrm{TiCl}_{4}+2 \mathrm{Mg} \rightarrow \mathrm{Ti}+2 \mathrm{MgCl}_{2}
$$

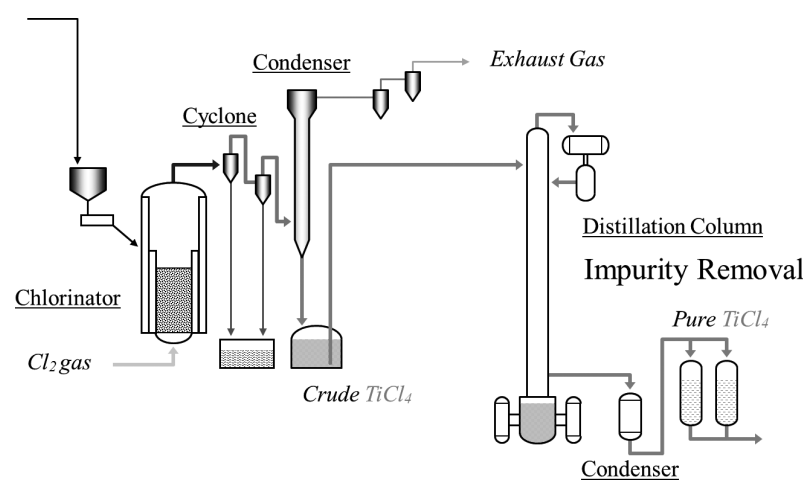

Fig. 3 Process flow for making $\mathrm{TiCl}_{4}$.

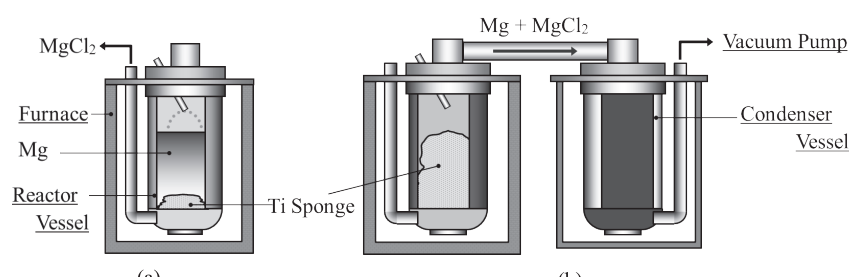

(a)

(b)

Fig. 4 Process flow of reduction and vacuum separation. (a) reduction process, (b) vacuum separation process.

precipitates to the bottom of the vessel due to its heavier density, and is periodically removed by pressurizing the vessel with argon gas.

After the reduction reaction is completed, vacuum separation is begun. The vessel is heated from the outside with an electric heater. A vacuum is generated inside the vessel. As a result, the magnesium chloride and the magnesium remaining in the titanium sponge evaporate, and high purity titanium sponge is obtained. The condenser vessel is reused for the next reduction reaction.

The reduction-vacuum separation are batch processes, so we improved per-batch yield and automated the process.

However, as production yield increases, it becomes difficult to control the heat balance. For example, sufficient heat output is required during reduction while efficient heat input is required in vacuum separation. We solved these issues by using computer simulation and improving the furnace. As a result, OTC raised what was the world's highest productivity even more, as now we are capable of producing more than 13 tons per batch.

\subsection{Electrolysis of magnesium chloride}

In this process, the magnesium chloride produced in the reduction process is decomposed into chlorine and magnesium by electrolysis. The chlorine is returned to the chlorination and distillation process, and the magnesium is returned to the reduction and vacuum separation process for reuse.

In order to increase the productivity of electrolysis, OTC switched from monopolar cells to multipolar cells (Fig. 5).

Now, OTC is using 5-pole cells and has dramatically improved productivity and, by way of that, current efficiency as well.

Magnesium chloride, which is produced as a by-product, 


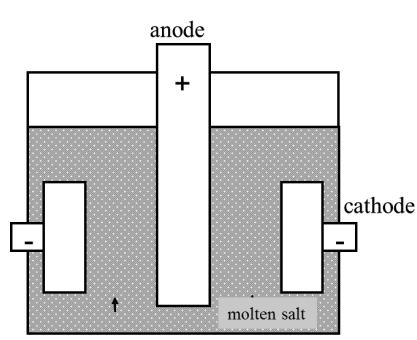

Monopolar cell

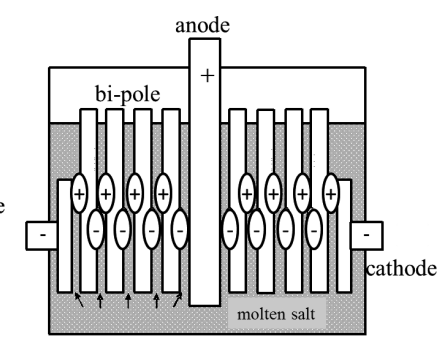

Multipolar cell
Fig. 5 OTC's electrolysis cells.

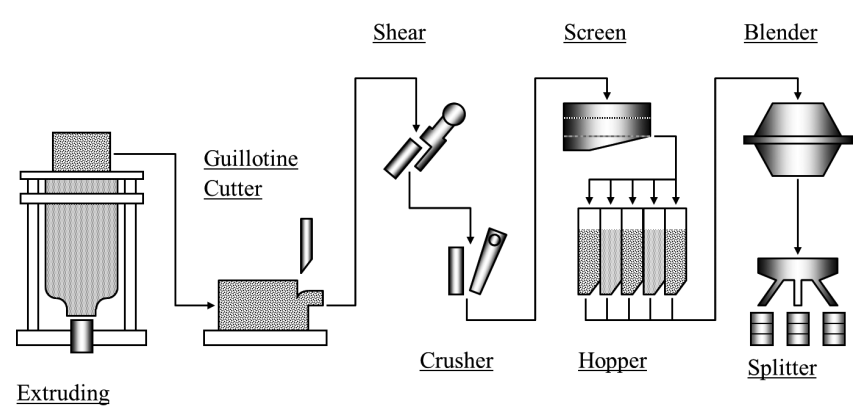

Fig. 6 Crushing, sizing and packaging process flow.

\subsection{Crushing and sizing of titanium sponge cake}

Figure 6 shows the crushing, sizing and packaging process flow. The titanium sponge is pushed out of the vessel and crushed into smaller pieces using a guillotine cutter, shear and crusher. It is then sized and packaged into drums.

\section{OTC Titanium Sponge Quality}

OTC's titanium sponge has the following features. First
Table 2 Quality of ASTM grade1, 4N5 and 5N grade (unit: ppm).

\begin{tabular}{lcccccccccc}
\hline & $\mathrm{Fe}$ & $\mathrm{Ni}$ & $\mathrm{Cr}$ & $\mathrm{Al}$ & $\mathrm{Si}$ & $\mathrm{As}$ & $\mathrm{Sn}$ & $\mathrm{Sb}$ & $\mathrm{O}$ & $\mathrm{N}$ \\
\hline ASTM Grade 1 & 2000 & - & - & - & - & - & - & - & 1800 & 300 \\
\hline 4N5 Grade & 15 & 3 & 3 & 3 & 3 & 3 & 3 & 3 & 400 & 30 \\
\hline 5N Grade & 5 & 1 & 1 & 1 & 1 & 1 & 1 & 1 & 300 & 30 \\
\hline
\end{tabular}

and foremost, it is ranked PQ grade, which is required especially for aircraft parts. It is also high quality, as OTC can stably produce $5 \mathrm{~N}$-purity titanium using our highly advanced Kroll method. (Table 2 shows some purity examples.) Regarding oxygen content, OTC can produce titanium sponge with oxygen levels of less than 200 ppm. ${ }^{7}$

\section{Conclusion}

Demand for titanium has been increasing. OTC will continue to serve these demands of the titanium industry. We think that the productivity of the Kroll process can be improved even more, so we will continue technical development of the Kroll process in the future.

\section{REFERENCES}

1) T. Hyodo et al:: Journal of MMIJ 123 (2007) 698-703.

2) A. Moriya et al.: Shigen-to-Sozai 109 (1993) 1164-1169.

3) T. Ikeshima, J. Iseki and T. Naritomi: Bulletin of the Japan Institute of Metals 24 (1985) 573-580.

4) J. Iseki et al:: Energy and Resources 6 (1985) 58-63.

5) T. Noda et al.: Bulletin of the Japan Institute of Metals 30 (1991) 150160.

6) J. Iseki et al:: Titanium and Zirconium 34 (1986) 103-109.

7) T. Iida et al:: Proceedings of the 13th World Conference on Titanium, (2015). 